\title{
Residual Astigmatism Threshold and Patient Satisfaction with Bifocal, Trifocal and Extended Range of Vision Intraocular Lenses (IOLs)
}

\author{
Francesco Carones \\ Carones Ophthalmology Center, Milan, Italy \\ Email: fcarones@carones.it
}

How to cite this paper: Carones, F. (2017) Residual Astigmatism Threshold and Patient Satisfaction with Bifocal, Trifocal and Extended Range of Vision Intraocular Lenses (IOLs). Open Journal of Ophthalmology, 7, 1-7.

https://doi.org/10.4236/ojoph.2017.71001

Received: November 16, 2016

Accepted: January 7, 2017

Published: January 10, 2017

Copyright $\odot 2017$ by author and Scientific Research Publishing Inc. This work is licensed under the Creative Commons Attribution International License (CC BY 4.0).

http://creativecommons.org/licenses/by/4.0/

(c) (†) Open Access

\begin{abstract}
Purpose: To compare the impact of induced astigmatism with four different types of multifocal intraocular lenses (MIOLs). Method: Prospective, comparative, interventional, mono-centered study, including 80 eyes of patients with implantation of four different MIOLs: AcrySof ReSTOR +2.5 D (20 eyes), AcrySof ReSTOR +3.0 D (20 eyes), AcrySof Panoptix (20 eyes) (Alcon Laboratories, Inc., Fort Worth, TX, USA), and Tecnis Symfony ZRX00 (Abbott Medical Optics, Santa Ana, USA) (20 eyes). Patients were followed up for 3 months after surgery. Major parameters were uncorrected (UDVA) and corrected (CDVA) distance visual acuity, subjective refraction and patient satisfaction. Results: Differences between IOLs with regard to the impact of the cylinder sign and axis on visual acuity and patient satisfaction were not significant. With mild added negative cylinder, AcrySof ReSTOR +2.5 D and Tecnis Symfony IOLs maintained the baseline visual acuity, while it was mildly reduced with AcrySof ReSTOR +3.0 D and Panoptix IOLs. With moderate induced cylinder, the Tecnis Symfony IOL maintained good visual acuity and patient associated satisfaction. Panoptix IOL was the IOL most affected by the induced astigmatism with regard to dissatisfaction and visual acuity. The highest tolerance to the astigmatic distortion and blurriness induced with a -1.50 D cylinder was obtained with the Tecnis Symfony IOL. Tecnis Symfony IOL showed less dissatisfaction and less reduction of visual acuity than the other MIOLs. Conclusion: Simulated residual cylinders after the implantation of the Tecnis Symfony IOL up to $1.0 \mathrm{D}$ have a very mild and not clinically relevant impact on visual acuity or patient satisfaction. The ERV IOL showed a better tolerance to unexpected postoperative residual errors than diffractive bifocal and trifocal IOLs.
\end{abstract}

\section{Keywords}

Multifocal IOL, Astigmatism Tolerance, Bifocal, Trifocal, Extended Range of 
Vision, Tecnis Symfony, Panoptix, AcrySof ReSTOR

\section{Introduction}

Multifocal intraocular lenses (MIOLs) are a reliable method for the surgical correction of presbyopia [1]. Currently, physicians have the choice between different optical designs. The most frequently used MIOLs are those based on a diffractive platform that sends light to the retina with a predefined light distribution to different foci [2]. The first designs were bifocal which allowed the patient to obtain a postoperative functional distance and near vision [3] [4]. Since some years, diffractive MIOL based on three useful focal distances (trifocal diffractive technology) is available to overcome the low performance of bifocal IOLs at intermediate distance. However, the limitations of diffractive designs in terms of photic phenomena and contrast sensitivity have led to the development of refractive MIOLs, such as rotationally asymmetric lenses that are able to provide a good visual performance with a higher percentage of transmitted light [5]. The extended range of vision (ERV) IOL is a new promising alternative to provide an effective and continuous range of optimum vision from far to near. This IOL is based on the combination of a diffractive pattern and the compensation for chromatic aberration and primary spherical aberration of the eye [6] [7] [8].

In spite of the well-known advantages of MIOLs, one major concern is the significant impact of residual astigmatisms on visual acuity (VA) and patient satisfaction. We have recently conducted a study to compare the impact of induced astigmatism with four different types of MIOLs.

\section{Patients and Methods}

We performed a prospective, comparative, interventional and single-center clinical study that included 80 eyes of 80 patients undergoing cataract surgery or refractive lens exchange (RLE) with the implantation of four different IOLs: AcrySof ReSTOR +2.5 D (20 eyes), AcrySof ReSTOR +3.0 D (20 eyes), Acrysof Panoptix (20 eyes) (Alcon Laboratories, Inc., Fort Worth, TX, USA), and Tecnis Symfony ZRX00 (Abbott Medical Optics, Santa Ana, USA) (20 eyes). Only patients with significant bilateral cataract and/or seeking for spectacle independence and with a pre-existing corneal astigmatism of less than $1.00 \mathrm{D}$ were included in the study. Likewise, only those patients with a postoperative uncorrected distance visual acuity (UDVA) or corrected distance visual acuity (CDVA) equal or higher than 1.2 (decimal scale) were included. Patients with any significant systemic diseases (diabetes, uncontrolled hypertension, etc.) were excluded, as well as eyes with any other pathology than cataract. These were the only inclusion and exclusion criteria.

Patients were examined preoperatively and at 1 day, 1 month, and 3 months after surgery. Postoperatively, the refractive status was objectively assessed by means of the OPD Scan III device (Nidek Technologies, Gamagori, Japan). 
UDVA, CDVA and subjective refraction at distance was evaluated under photopic conditions $\left(85 \mathrm{~cd} / \mathrm{m}^{2}\right)$ by an experienced practitioner using a phoropter. Once subjective refraction was measured and CDVA assessed as equal or better than 1.2 , the experienced practitioner added cylinder lenses $(0.25 \mathrm{D}$ to $1.50 \mathrm{D}$ in 0.25 D steps, plus and minus values, 90 and 180 degrees) and measured CDVA again at each step. For each measurement, subjective patient satisfaction was assessed by means of a color code (green = very satisfied; yellow = moderately satisfied; orange $=$ not satisfied; red $=$ not at all satisfied). Correlation and multivariate regression analysis between the four groups was carried out using the specific function in an Excel software spreadsheet, to assess the impact of astigmatism on both VA and patient satisfaction.

The Restor +3.0 D (model SN6AD1) and the ReSTOR +2.5 D are aspheric bifocal IOLs that combine an apodized diffractive region and a refractive region (Alcon AcrySof IQ ReSTOR intraocular lens patient information brochure: Alcon Inc. 2008). Both IOLs are made of the same hydrophobic acrylic material. The Restor +3 D IOL has nine concentric gradual diffractive steps from the centre to the periphery within the central $3.6 \mathrm{~mm}$ optical zone, providing a near add of +3.0 D at the lens plane and $+2.3 \mathrm{D}$ add at the corneal plane.

PanOptix is an aspheric non-apodized diffractive trifocal IOL correcting for a corneal spherical aberration of $-0.1 \mu \mathrm{m}$ and made of the same material than AcrySof ReSTOR IOLs. It distributes light energy to three focal points under both small and large pupil conditions. It uses zero, second, and third non-sequential diffraction orders for obtaining the distance, intermediate $(60 \mathrm{~cm})$, and near foci $(42 \mathrm{~cm})$, respectively, and the energy at the first diffractive order is re-distributed to optimize the performance at the three other focal points.

The Tecnis Symfony ZXR00 has an achromatic diffractive pattern that elongates the range of vision of the eye and compensates for the chromatic aberration of the cornea. Specifically, the lens has a biconvex wave front-designed anterior aspheric surface and a posterior achromatic diffractive surface. It is made of a UV-blocking hydrophobic acrylic material.

\section{Results}

There was no difference between IOLs with regard to the impact of the cylinder sign and axis on visual acuity and patient satisfaction $(r=0.211)$. When the added cylinder was negative and equal or less than $0.50 \mathrm{D}$, AcrySof ReSTOR +2.5 D and Tecnis Symfony IOLs maintained the baseline visual acuity (1.2), while it was mildly reduced with the AcrySof ReSTOR $+3.0 \mathrm{D}$ and PanOptix IOLs from 1.2 to 1.0 (Figure 1).

If the induced cylinder was $-1 \mathrm{D}$, the Tecnis Symfony IOL still achieved a good visual acuity (0.8) (Figure 1), with a high level of associated satisfaction (Table 1). Likewise, both AcrySof ReSTOR IOLs showed a moderate reduction of VA (0.7) and some degree of dissatisfaction with $-1 \mathrm{D}$ of cylinder. On the contrary, PanOptix IOL was the IOL most affected by the induced astigmatism, showing the highest level of dissatisfaction and a significant lowering of visual 


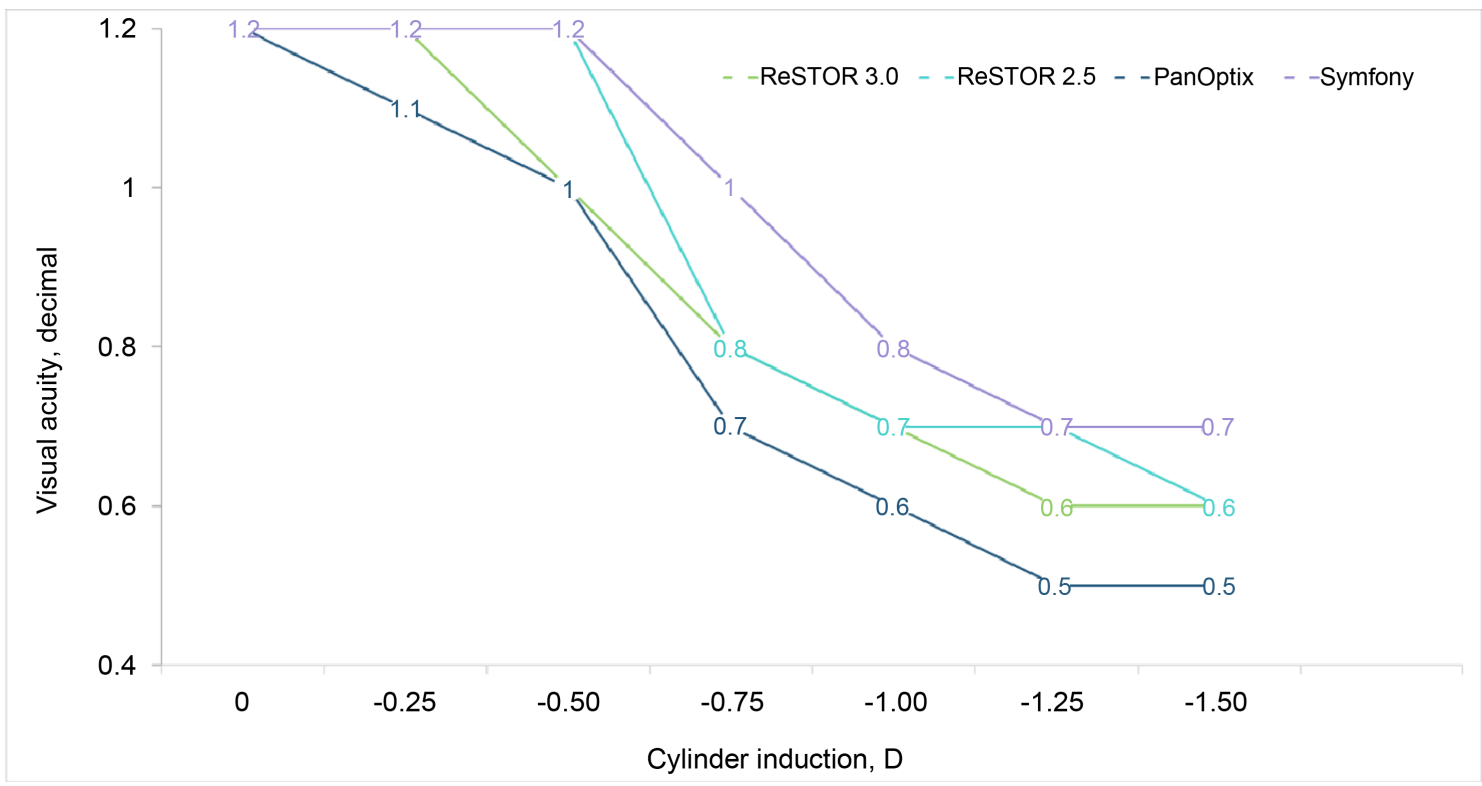

Figure 1. Visual acuity with the four MIOLs after the induction of different values of negative cylinder. Values are reported as median ones.

Table 1. Patient satisfaction scores with the four MIOLs after the induction of different values of negative cylinder (green = very satisfied; yellow = moderately satisfied; orange = not satisfied; red $=$ not at all satisfied). Values are reported as median, with range in brackets.

\begin{tabular}{ccccccc}
\hline Minus values & $-0.25 \mathrm{D}$ & $-0.50 \mathrm{D}$ & $-0.75 \mathrm{D}$ & $-1.00 \mathrm{D}$ & $-1.25 \mathrm{D}$ & $-1.50 \mathrm{D}$ \\
\hline ReSTOR 3.0 & $1.2(1.1-1.2)$ & $1.0(0.9-1.2)$ & $0.8(0.7-1.0)$ & $0.7(0.6-0.7)$ & $0.6(0.6)$ & $0.6(0.6-0.6)$ \\
ReSTOR 2.5 & $1.2(1.2)$ & $1.2(1.0-1.2)$ & $0.8(0.7-1.0)$ & $0.7(0.7)$ & $0.7(0.6-0.7)$ & $0.6(0.5-0.7)$ \\
PanOptix & $1.1(1.1-1.2)$ & $1.0(0.9-1.0)$ & $0.7(0.7-0.8)$ & $0.6(0.5-0.7)$ & $0.5(0.5-0.6)$ & $0.5(0.4-0.5)$ \\
Symfony & $1.2(1.2)$ & $1.2(1.2)$ & $1.0(0.8-1.0)$ & $0.8(0.7-0.9)$ & $0.7(0.6-0.8)$ & $0.7(0.6-0.7)$ \\
\hline
\end{tabular}

acuity (0.6) (Figure 1). The highest tolerance to the astigmatic distortion and blurriness induced with a $-1.50 \mathrm{D}$ cylinder was obtained with the Tecnis Symfony IOL. In this situation, this IOL was still able to provide a good visual acuity (0.7) and a moderate patient satisfaction (Figure 1 and Table 1).

These results are very similar if the sign of the induced astigmatism was positive (Figure 2 and Table 2). Only a higher level of relevant dissatisfaction and an earlier impact on visual acuity have been detected with this type of cylinder induction. Specifically, with an induced cylinder of $+1.0 \mathrm{D}$, both bifocal AcrySof IOLs showed a reduction in visual acuity from baseline to 0.6 , and the PanOptix IOL from baseline to 0.5 . The level of dissatisfaction was very high in all cases. Only the Tecnis Symfony IOL was able to show an only moderate dissatisfaction and a lower reduction in visual acuity (from baseline to 0.7 ) (Figure 2 and Table 2). Overall, The Tecnis Symfony IOL was less correlated to decreased VA and reduced patient satisfaction $(\mathrm{r}=0.411)$ than the AcrySof ReSTOR $2.5 \mathrm{D}(\mathrm{r}=$ 0.501), the AcrySof ReSTOR 3.0 D ( $\mathrm{r}=0.505)$ and the AcrySof PanOptix $(\mathrm{r}=$ 0.654). Significance was found only between the Tecnis Symfony and the AcrySof PanOptix IOLs. 


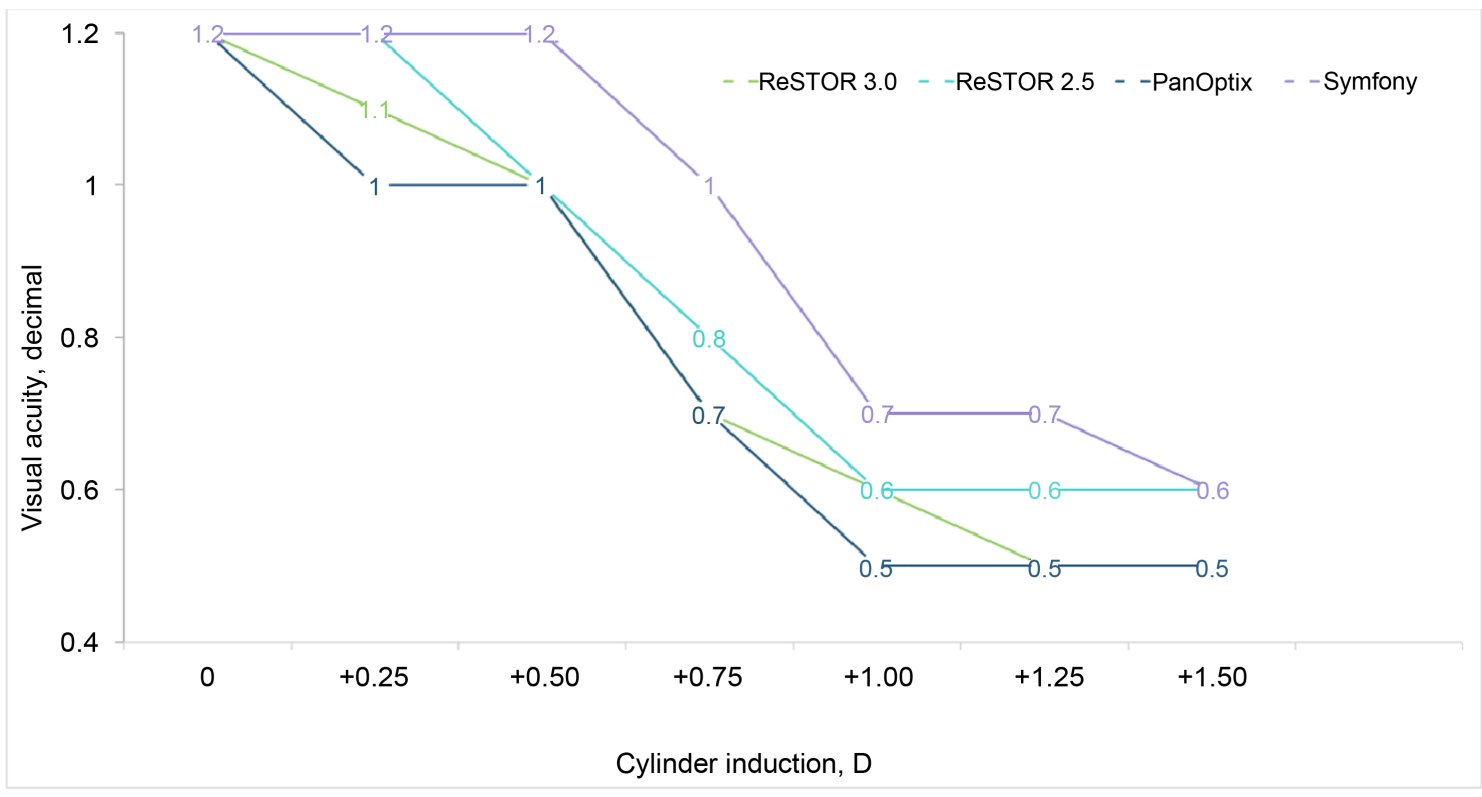

Figure 2. Visual acuity with the four MIOLs after the induction of different values of positive cylinder. Values are reported as median ones.

Table 2. Visual acuity and patient satisfaction scores with the four MIOLs after the induction of different values of positive cylinder (green = very satisfied; yellow = moderately satisfied; orange $=$ not satisfied; red $=$ not at all satisfied). Values are reported as median, with range in brackets.

\begin{tabular}{ccccccc}
\hline Plus values & $+0.25 \mathrm{D}$ & $+0.50 \mathrm{D}$ & $+0.75 \mathrm{D}$ & $+1.00 \mathrm{D}$ & $+1.25 \mathrm{D}$ & $+1.50 \mathrm{D}$ \\
\hline ReSTOR 3.0 & $1.1(1.1-1.2)$ & $1.0(0.9-1.2)$ & $0.7(0.7-0.9)$ & $0.6(0.6-0.7)$ & $0.5(0.5-0.6)$ & $0.5(0.4-0.5)$ \\
ReSTOR 2.5 & $1.2(1.2)$ & $1.0(1.0-1.2)$ & $0.8(0.7-1.0)$ & $0.6(0.6-0.7)$ & $0.6(0.5-0.6)$ & $0.6(0.5-0.6)$ \\
PanOptix & $1.1(1.0-1.2)$ & $1.0(0.9-1.0)$ & $0.7(0.6-0.8)$ & $0.5(0.5-0.7)$ & $0.5(0.5-0.6)$ & $0.5(0.4-0.5)$ \\
Symfony & $1.2(1.2)$ & $1.2(1.2)$ & $1.0(0.8-1.0)$ & $0.7(0.7-0.9)$ & $0.7(0.6-0.8)$ & $0.6(0.6-0.7)$ \\
\hline
\end{tabular}

\section{Discussion}

Regardless of the type of MIOL, one of the major concerns for surgeons is the presence of residual astigmatism that is considered a source of dissatisfaction after the implantation of a MIOL [8]. Small amounts of astigmatism may limit the visual performance significantly [9]. Thus, so far, astigmatism had to be completely corrected in order to obtain the maximum efficiency of a MIOL [10]. To the best of our knowledge there is a lack of scientific evidence about the impact of residual astigmatism with IOLs based on different optical designs. The purpose of our study was the assessment of the astigmatism threshold for different presbyopia correcting IOLs, and the impact on patient satisfaction.

In our study, no significant differences between with-the-rule and against-therule induced astigmatism were found. All the studied MIOLs provided excellent visual acuities with induced cylinders of up to $0.50 \mathrm{D}$, with both minus and plus sign. When cylinder values higher than $0.50 \mathrm{D}$ were added, the impact on visual acuity depended on the type of IOL, with greater impact on positive additions than on negative. Likewise, satisfaction scores dropped significantly when cylin- 
ders equal or higher than 1.0 D were added. It should be considered that MIOLs distribute light to two or more foci and this distribution may be distorted or altered by the presence of the asymmetric light distribution generated by an uncorrected astigmatism.

The ERV IOL seemed to be the least sensitive to induced blurriness with regard to visual acuity and satisfaction scores. The acceptable threshold of induced astigmatism was found to be $1.0 \mathrm{D}$. It should be considered that the ERV IOL does not distribute light to distinct foci but provides a continuous range of vision. The behaviour of both bifocal IOLs is very similar, although AcrySof ReSTOR +2.50 D IOL seemed to be slightly less sensitive to induced astigmatism than AcrySof ReSTOR +3.0 D. For both IOLs an acceptable threshold of induced astigmatism of $0.75 \mathrm{D}$ was found. The trifocal IOL was the most sensitive in terms of reduction of visual acuity and patient satisfaction when adding a cylinder. The acceptable threshold was found to be $0.50 \mathrm{D}$. Therefore, the residual astigmatism seems to have more impact on visual performance when the MIOL distributes light to a larger number of foci.

\section{Conclusion}

In summary, simulated residual cylinders after the implantation of the Tecnis Symfony IOL up to $1.0 \mathrm{D}$ have a very mild and not clinically relevant impact on visual acuity or patient satisfaction. Thus, the ERV IOL shows a better tolerance to unexpected postoperative residual errors than diffractive bifocal and trifocal IOLs.

\section{References}

[1] Charman, W.N. (2014) Developments in the Correction of Presbyopia II: Surgical Approaches. Ophthalmic and Physiological Optics, 34, 397-426. https://doi.org/10.1111/opo.12129

[2] Percival, S.P. (1989) Prospective Study of the New Diffractive Bifocal Intraocular Lens. Eye, 3, 571-575. https://doi.org/10.1038/eye.1989.89

[3] Alió, J.L., Plaza-Puche, A.B., Piñero, D.P., Amparo, F., Jiménez, R., Rodríguez-Prats, J.L., Javaloy, J. and Pongo, V. (2011) Optical Analysis, Reading Performance, and Quality-of-Life Evaluation after Implantation of a Diffractive Multifocal Intraocular Lens. Journal of Cataract \& Refractive Surgery, 37, 27-37. https://doi.org/10.1016/j.jcrs.2010.07.035

[4] Alfonso, J.F., Fernández-Vega, L., Señaris, A. and Montés-Micó, R. (1930) Prospective study of the Acri.LISA Bifocal Intraocular Lens. Journal of Cataract \& Refractive Surgery, 2007, 33. https://doi.org/10.1016/j.jcrs.2007.06.067

[5] Kawamorita, T., Uozato, H., Aizawa, D., Kamiya, K. and Shimizu, K. (2009) Optical Performance in Rezoom and Array Multifocal Intraocular Lenses in Vitro. Journal of Refractive Surgery, 25, 467-469. https://doi.org/10.3928/1081597X-20090422-10

[6] Weeber, H.A. and Piers, P.A. (2012) Theoretical Performance of Intraocular Lenses Correction Both Spherical and Chromatic Aberration. Journal of Refractive Surgery, 28, 48-52. https://doi.org/10.3928/1081597X-20111103-01

[7] Artal, P., Manzanera, S., Piers, P. and Weeber, H. (2010) Visual Effect of the Combined Correction of Spherical and Longitudinal Chromatic Aberrations. Optics EX- 
press, 18, 1637-1648. https://doi.org/10.1364/OE.18.001637

[8] De Vries, N.E., Webers, C.A., Touwslager, W.R., Bauer, N.J., de Brabander, J., Berendschot, T.T. and Nuijts, R.M. (2011) Dissatisfaction after Implantation of Multifocal Intraocular Lenses. Journal of Cataract \& Refractive Surgery, 37, 859865. https://doi.org/10.1016/j.jcrs.2010.11.032

[9] Macsai, M.S. and Fontes, B.M. (2008) Refractive Enhancement Following Presbyopia-Correcting Intraocular Lens Implantation. Current Opinion in Ophtha- Imology, 19, 18-21. https://doi.org/10.1097/ICU.0b013e3282f14d9f

[10] Abdelghany, A.A. and Alió, J.L. (2014) Surgical Options for Correction of Refractive Error Following Cataract Surgery. Eye Vis (London), 1, 2.

https://doi.org/10.1186/s40662-014-0002-2

Submit or recommend next manuscript to SCIRP and we will provide best service for you:

Accepting pre-submission inquiries through Email, Facebook, LinkedIn, Twitter, etc. A wide selection of journals (inclusive of 9 subjects, more than 200 journals)

Providing 24-hour high-quality service

User-friendly online submission system

Fair and swift peer-review system

Efficient typesetting and proofreading procedure

Display of the result of downloads and visits, as well as the number of cited articles Maximum dissemination of your research work

Submit your manuscript at: http://papersubmission.scirp.org/

Or contact ojoph@scirp.org 